\title{
AN ALTERNATIVE PROOF OF ELEZOVIĆ-GIORDANO-PEČARIĆ'S THEOREM
}

\author{
BAI-Ni GUO AND FENG QI
}

Abstract. In this paper, an alternative proof is supplied for monotonicity and convexity of the function $z_{s, t}(x)=[\Gamma(x+t) / \Gamma(x+s)]^{1 /(t-s)}-x$ with $z_{s, s}(x)=e^{\psi(x+s)}-x$, where $\Gamma$ is the classical Euler's gamma function, $s$ and $t$ are real numbers with $t-s \neq \pm 1, \alpha=\min \{s, t\}$ and $x \in(-\alpha, \infty)$.

Mathematics subject classification (2010): 26A48, 26A51, 26D20, 33B15.

Keywords and phrases: An alternative proof, monotonicity, convexity, ratio of two gamma functions, convolution theorem of Laplace transforms.

\section{REFERENCES}

[1] CH.-P. Chen, Monotonicity and convexity for the gamma function, J. Inequal. Pure Appl. Math., 6, 4 (2005), Art. 100; Available online at URL: http://jipam.org/article.php?sid=574.

[2] N. Elezović, C. Giordano And J. PeČArić, The best bounds in Gautschi's inequality, Math. Inequal. Appl., 3 (2000), 239-252.

[3] W. GAUTSCHI, Some elementary inequalities relating to the gamma and incomplete gamma function, J. Math. Phys., 38 (1959/60), 77-81.

[4] B.-N. GUO AND F. QI, Properties and applications of a function involving exponential functions, Commun. Pure Appl. Anal., 8, 4 (2009), 1231-1249.

[5] B.-N. GUO AND F. QI, Two new proofs of the complete monotonicity of a function involving the psi function, Bull. Korean Math. Soc., 47, 1 (2010), 103-111; Available online at URL: http://dx.doi.org/10.4134/BKMS.2010.47.1.103.

[6] D. Kershaw, Some extensions of W. Gautschi's inequalities for the gamma function, Math. Comp., 41 (1983), 607-611.

[7] I. LaZarević and A. Lupaş, Functional equations for Wallis and Gamma functions, Publ. Elektrotehn. Fak. Univ. Beograd. Ser. Electron. Telecommun. Automat. No. 461-497 (1974), 245-251.

[8] W. Magnus, F. Oberhettinger, And R.P. Soni, Formulas and Theorems for the Special Functions of Mathematical Physics, Springer, Berlin, 1966.

[9] F. QI, Bounds for the ratio of two gamma functions, J. Inequal. Appl., 2010 (2010), Article ID 493058, 84 pages; Available online at URL: http://dx.doi.org/10.1155/2010/493058.

[10] F. QI, Bounds for the ratio of two gamma functions-From Wendel's limit to Elezović-GiordanoPečarić's theorem, Available online at URL: http: //arxiv.org/abs/0902.2514.

[11] F. QI, Three classes of logarithmically completely monotonic functions involving gamma and psi functions, Integral Transforms Spec. Funct., 18, 7 (2007), 503-509.

[12] F. QI, Three-log-convexity for a class of elementary functions involving exponential function, J. Math. Anal. Approx. Theory, 1, 2 (2006), 100-103.

[13] F. QI AND B.-N. GUO, A class of completely monotonic functions involving divided differences of the psi and polygamma functions and some applications, Available online at URL: http://arxiv.org/abs/0903.1430.

[14] F. QI AND B.-N. GUO, An alternative proof of Elezović-Giordano-Pečarić's theorem, Available online at URL: http://arxiv.org/abs/0903.1174. 
[15] F. QI AND B.-N. GuO, Completely monotonic functions involving divided differences of the di- and tri-gamma functions and some applications, Commun. Pure Appl. Anal., 8, 6 (2009), 1975-1989; Available online at URL: http://dx.doi.org/10.3934/cpaa.2009.8.1975.

[16] F. QI, B.-N. GUO AND CH.-P. CHEN, Some completely monotonic functions involving the gamma and polygamma functions, J. Aust. Math. Soc., 80 (2006), 81-88.

[17] F. QI, B.-N. GuO AND CH.-P. Chen, The best bounds in Gautschi-Kershaw inequalities, Math. Inequal. Appl., 9, 3 (2006), 427-436.

[18] G.N. Watson, A note on gamma functions, Proc. Edinburgh Math. Soc., 11, 2 (1958/1959), Edinburgh Math Notes No. 42 (misprinted 41) (1959), 7-9.

[19] E.W. Weisstein, Laplace Transform, From MathWorld-A Wolfram Web Resource; Available online at URL: http: //mathworld.wolfram.com/LaplaceTransform.html.

[20] J.G. Wendel, Note on the gamma function, Amer. Math. Monthly, 55, 9 (1948), 563-564. 